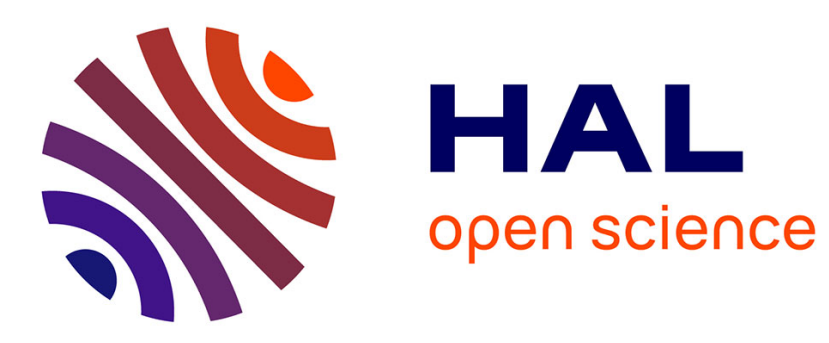

\title{
The Development of TE-Cap: an Assistance Environment for Online Tutors
}

Elise Garrot, Sébastien George, Patrick Prévôt

\section{To cite this version:}

Elise Garrot, Sébastien George, Patrick Prévôt. The Development of TE-Cap: an Assistance Environment for Online Tutors. Second European Conference on Technology Enhanced Learning (EC-TEL 2007), Sep 2007, Crete, Greece. pp.481-486. hal-00178426

\section{HAL Id: hal-00178426 \\ https://hal.science/hal-00178426}

Submitted on 8 Jun 2009

HAL is a multi-disciplinary open access archive for the deposit and dissemination of scientific research documents, whether they are published or not. The documents may come from teaching and research institutions in France or abroad, or from public or private research centers.
L'archive ouverte pluridisciplinaire HAL, est destinée au dépôt et à la diffusion de documents scientifiques de niveau recherche, publiés ou non, émanant des établissements d'enseignement et de recherche français ou étrangers, des laboratoires publics ou privés. 


\title{
The Development of TE-Cap: An Assistance Environment for Online Tutors
}

\author{
Elise Garrot, Sébastien George, and Patrick Prévôt \\ LIESP Laboratory, INSA-Lyon, F-69621, France \\ \{elise.garrot, sebastien.george; patrick.prevot\} ainsa-lyon.fr
}

\begin{abstract}
Our research is based on the hypothesis that the most important problem that has to be solved, so as to help tutors, is the gap between required competencies of distance tutoring and the lack of training and recommendations given to them on the role they have to play in the learning process. In this article, we detail the development of the assistance environment for tutors named TE-Cap (Tutoring Experience Capitalization). We first present results of interviews conducted with tutors to define their explicit and implicit needs. We then detail functionalities of the TE-Cap (Tutoring Experience Capitalization) platform we developed and first results of an experiment, in terms of computing functionalities and interface design. Finally, we present some future directions of our research.
\end{abstract}

Keywords: Assistance Environment for Tutor, Community of Practice, Experiences sharing, Knowledge Management.

\section{Research Issues}

Nowadays, there is an obvious need of assistance for tutors that we define as those who monitor students' activities at distance. Our research is based on the hypothesis that the most important problem that has to be solved, so as to help tutors, is the gap between required competencies of distance tutoring [1] (matter expertise, technical, pedagogical, information and communication skills) and the lack of training and the recommendations given to them on the role they have to play in the learning process. Formation methods remain specific to each campus, and therefore quite isolated and rather ad-hoc [2]. This hypothesis is illustrated by the fact that for several years, we can notice the creation of several communities of practice of tutors, like $\mathrm{t} @ \mathrm{~d}$ (http://jacques.rodet.free.fr/), that highlight the need to provide some help to these actors, beyond the frontiers defined by institutions. In fact, in most educational institutions, tutors have an environment which proposes forums, chat or blog in order to incite them to interact together and with students. In some cases, these environments propose an assistant tool to help tutors to monitor students' activities and to retrieve traces of their work. We think that these environments and tools can be useful, when they are adopted by tutors [3], but are not sufficient. Firstly, tutors cannot interact with tutors of other institutions. Secondly, assistance tools depend on the environment, so it is quite difficult to use a same tool in various contexts. Furthermore, it seems useless to provide information about students to tutors if they do not know the 
theme of their work. Basing on this hypothesis, our research aims at developing an innovative assistance environment for tutors going over existing frontiers (e.g. institution, training program, teaching subject), which takes into account and values all tutors' skills, to improve their efficiency and the way they work.

One of the difficulties of our research is to find or create relations between actors from different institutions. Indeed, within the context of one institution, there are many subjects that can form the basis of interactions: common courses, common goals, common learners to monitor, etc. But, when we pass beyond the borders of the institution, which subject will create interactions between tutors? The environment that we develop must be itself the catalyst of the interactions, in order to lead tutors to help each other. Another important difficulty to overcome is the determination of tutors' needs in terms of help or assistance, independently of the institution to which they belong. It implies the development of an environment which responds to needs which are not precisely identified or not expressed by these actors. Since tasks assigned to tutors vary according to institutions, our objective is not to develop an environment that would optimize some tasks, to which correspond recognizable needs. The finality of the system we develop is to support an emerging helping process between tutors that could not be well defined a priori. The development of the assistance system TE-Cap (Tutoring Experience Capitalization) relies on a participative and iterative design process based on the framework proposed by Mackay and Fayard [4]. The aim is to give birth gradually to needs and expectations of tutors, so as to make evolve the system functionalities at the same time as the needs are expressed.

\section{Definition of Explicit and Implicit Needs}

The first development life-cycle aimed at knowing tutors activities and practices and identifying their needs and expectations by interviewing them. We conducted seven interviews with tutors of different institutions, with different backgrounds and from different disciplines (educational sciences, computer science, training to set-up blended learning, use of ICT in education and training). These interviews were based on a literature survey on tutor roles in distance learning [5]. Several questions guided these interviews: What are the experiences and the initial skills of tutors? What training was given to them? How do they build their practices? Do they exchange them? What is the nature of the interactions between them?

As a result, we determined tutors' needs and expectations and, moreover, a model of the factors in relation with a practice of tutoring. This model summarizes the vocabulary used by tutors in their day-to-day practice. So, a tutoring practice can be bound to the institutional context, to the teaching situation or to the tutor's profile. We give more details in [6]. By analysing interviews retranscription, we highlighted some lacks for tutors:

- Lack of training to become a tutor, so they develop their own practices, which is very difficult for a novice.

- Lack of interactions between tutors of an institution and of various institutions.

- Lack of professional identity, so tutors do not know of what their work consists in.

- Lack of practices sharing between tutors. 
We also raised several points important to exploit in tutors' practice and profile:

- The variety of the careers and training of the tutors: it implies a variety of skills (e.g. educational, technical, expertise of the subject) that can be exploited to facilitate the sharing and the development of tutors' skills.

- The adoption of practices of capitalization by building a repository to hold their role with more efficiency. A shared capitalization would be a source of inspiration for many tutors, in particular for the novices.

- Numerous interests for sharing practices.

With regards to the literature, we decided to base our work on the concept of Community of Practice (CoP) developed by Wenger [7]. We detail this concept and the reasons of our choice in [6]. We consider that in the framework of a CoP, tutors will be able to share and develop their experiences, competencies and practices. We also base the development of our experiment prototype on the concept of knowledge management, in order to store and retrieve the explicit and tacit knowledge produced by the $\mathrm{CoP}$ of tutors [8]. The environment has to support the following needs:

- To facilitate the perception of the community members.

- To facilitate interactions, experiences sharing and mutual aid between tutors.

- To encourage the reflexivity of tutors on their practices.

- To use a vocabulary common to the CoP (in our case adapted to tutoring).

- To capitalize the exchanges between tutors in a contextual way.

- To register the present expertise in the community.

- To adopt an effective classification of knowledge (messages, documents ...).

- To make the members participate in the evolution of the platform.

\section{TE-Cap Development and Experiment Results}

This second cycle leads to the development of the assistance environment TE-Cap (Tutoring Experience Capitalization) based on the requirements previously identified. The conception of the platform relies on the CMS (Content Management System) opensource Joomla!. We opted for this CMS according to some criteria and among a consequent list of existing CMS (http://cmsmatrix.org/). The main reasons of this choice are, on the one hand, that it proposes basic functionalities which thus do not need to be developed again (such as articles, documents and users management) and, on the other hand, that its functionalities are based on independent components, so the evolution capacities and the modularity of TE-Cap is largely facilitated. We modified some components and developed some others so as to answer needs identified.

\subsection{TE-Cap Functionalities}

1. Perception and sharing among community members: the environment displays the list of tutors who belong to the community. For each member, it is possible to consult its profile and to send to another a personal e-mail directly from the interface. In this way, a tutor novice in a domain of skill (technical or educational skills or skills concerning contents) can ask directly for help a more expert tutor in this 
domain. The visualization of members' profiles brings conviviality to the site, inciting to participate in the community life.

2. Personal space within the community portal: by connecting to the platform, the tutor can display messages, documents and Web links which s/he proposed to the community, with as indication the number of times they were viewed by other tutors (Fig. 1). S/he can also consult the comments made on a message. Tutors have the choice to diffuse or not the messages they write. This functionality plays the role of a log book which can contain private and public parts. Furthermore, before validating a message, the tutor has to precise his intention: testimony, discussion or ask for help. This constrains him/her to have a reflection on its intention and creates a first classification of messages. Before sending a message, the tutor has to classify it with a dedicated interface which is presented in the next section.

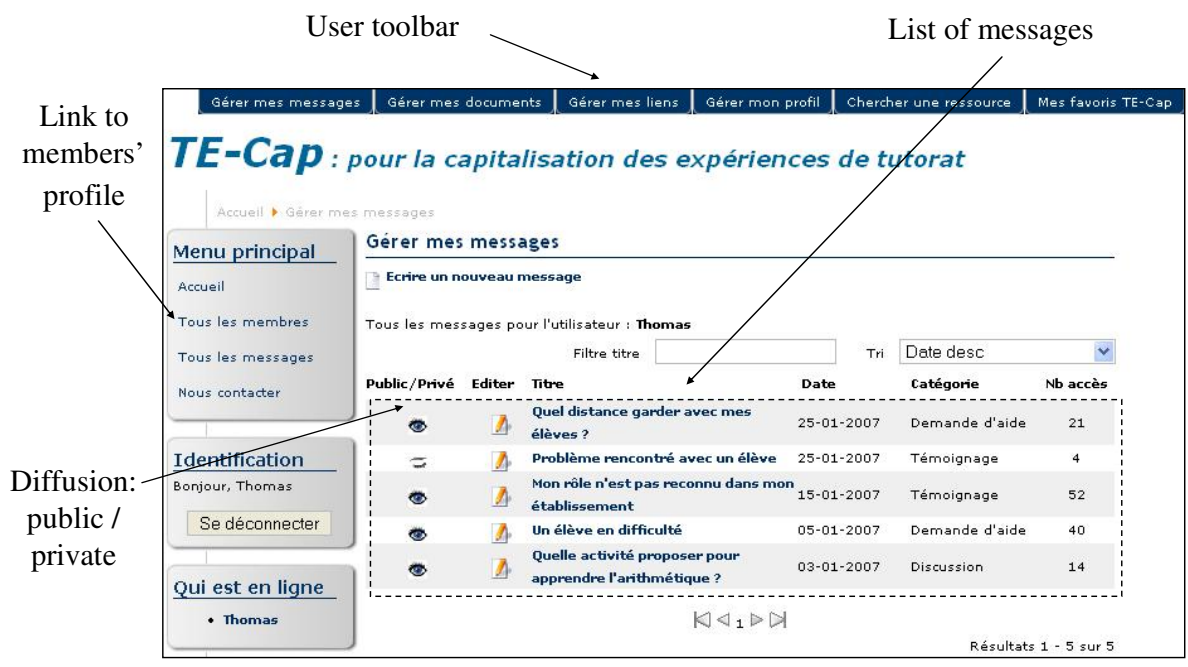

Fig. 1. The personal space of messages publication

3. Knowledge capitalization: with the need of management of the knowledge produced by the community, we developed a component of knowledge classification, integrated in the CMS. The classification is based on the model developed in the first cycle and uses a vocabulary adapted to the community. The classification appears in the form of a dynamic arborescence. This component offers two main functionalities:

- When a tutor sends a message, a document or a Web link, he has to choose the corresponding subjects in the dynamic arborescence. For example, if a tutor asks for help because s/he does not know how to react in front of a learner in trouble within a workgroup, s/he can check the box "In trouble" in the subject "Position inside the group " in the part "Concerned learners".

- The tutor can look for all the types of resources relating to one or several subjects in relation with tutoring. If s/he finds an interesting resource, s/he can 
consult it and add it to his/her favourites. Furthermore, s/he can choose to react to a message, to bring assistance or to pursue a discussion for instance.

The classification tool is in the heart of the participative design of the environment. Tutors can make evolve the initial classification, by proposing new categories. These are proposed to the moderator of the community who decides to add the proposed category or not. Furthermore, the categories used by tutors are recorded, which allows for example to highlight useless ones. This approach offers the possibility to tutors to really adopt the environment, that is essential if we want them to use it.

\subsection{First Results of the Experiment}

The experiment of the prototype involved the participation of twelve tutors from six countries: Costa Rica, Senegal, Algeria, France, Tunisia and Canada. We have chosen tutors from different institutions and disciplines (e.g. educational science, computer science, mathematics, pedagogy, project management). They used the prototype TECap during two months and tried to integrate it into their practice.

The experiment has just finished. We have defined criteria to observe the response of this prototype to tutors' needs. These criteria are based on the theories that we have chosen to develop (communities of practice and knowledge management). Hence the three categories of criteria are: usability and sociability of the environment [9], measure of the creating and sharing knowledge activities [10] and adoption of the environment by users [3]. These criteria are measured by retrieving and analyzing traces of use and by a questionnaire addressed to tutors.

By observing the day-to-day environment use, we can already notice that tutors did not interact a lot. Some messages have been posted but there were not many answers to them. We also notice that there were only two documents proposed and no Web link. Is it because they do not have documents to exchange? Or is it because the environment is not convenient for them to exchange resources? The analysis of use traces is not finished yet and we will have more results with the return of questionnaires sent to tutors. We make three first hypotheses to explain these observations:

- There were not enough members in the community (12 tutors) to generate high interactions between tutors. It implies that there is a minimal size for the community to observe the emergence of rich interactions.

- Tutors prefer to receive information rather than to have to connect to the environment to see new messages, new comments or new documents. So, we propose to add notification of information by integrating the technology of syndication feed.

- The usability of the interface we have developed to classify and search resources is not well adapted to tutors. The presentation of the classification in the form of a dynamic arborescence has to be modified and improved.

\section{Conclusion and Futures Directions}

In this article, we developed a participative and iterative process adopted to develop the of the assistance environment for tutors named TE-Cap. Tutors interviews gave information on their explicit and implicit needs. We then referred to theory to suppose global implicit needs, so as to develop a first prototype. The experiment of this 
prototype was not as successful as we supposed, because tutors did not interact a lot inside the environment. So we will not have enough quantitative information by the way of traces of use of the environment. That is why it is necessary to address a questionnaire to tutors to have more qualitative information.

Concerning the development of TE-Cap, we will base the future cycle on the results of the experiment. It consists in offering to actors, on the one hand, the tools to manage all the knowledge produced by the members' participation in the community, and on the other hand, the tools to create interactions in regards to these knowledge. The development of TE-Cap will be also centered on an adapted interface, which will be more attractive, intuitive and efficient for tutors in their practice. In the end of the third cycle, we will determine the adequacy of the final environment tutors' needs and expectations.

\section{References}

1. McPherson, M., Nunes, M.B.: The role of tutors as an integral part of online learning support. European Journal of Open, Distance and E-Learning (EURODL I (2004) retrieved March 28, 2007 from /www.eurodl.org/materials/contrib/2004/Maggie_MsP.html

2. Class, B., Schneider, D.: Tutorat, socio-constructivisme et capitalisation des connaissances dans un portail communautaire utilisé en éducation à distance. Colloque Eifad (École d'Ingénierie de la Formation à Distance). Poitiers (2004) retrieved March 28, 2007 from http://www.cned.fr/colloqueeifad/Documents/Class_Schneider.pdf

3. West, R.E., Waddoups, G., Graham, C.R.: Understanding the experiences of instructors as they adopt a course management system. Educational Technology Research and Development 55, 1-26 (2007)

4. Mackay, W.E., Fayard, A-L.: HCI, Natural Science and Design: A Framework for Triangulation Across Disciplines. In: Proceedings of ACM DIS ‘97: Designing Interactive Systems. Amsterdam, pp. 223-234. ACM Press, New York (1997)

5. Garrot, E., George, S., Prévôt, P.: A Platform to Support a Virtual Community of Tutors in Experience Capitalizing. In: proceedings of Web Based Communities Conference (WBC 2007) Salamanca, Spain pp. 103-110 (2007)

6. Garrot, E., George, S., Prévôt, P.: TE-Cap: une plate-forme support au partage et à la capitalisation d'expériences entre tuteurs. In: Proceedings of EIAH 2007 Conference. Lausanne (to be published, 2007)

7. Wenger, E.: Communities of practice: Learning, meaning, and identity. Cambridge University Press, Cambridge, U.K., New York (1998)

8. Nonaka, I., Takeuchi, H.: The knowledge creating company. Oxford Press, New York, USA (1995)

9. Preece, J.: Online Communities: Designing Usability, Supporting Sociability. John Wiley \& Sons, Chichester, UK (2000)

10. Koh, J., Kim, Y.G.: Knowledge sharing in virtual communities: an e-business perspective. Expert Systems with Applications 26(2), 155-166 (2004) 